\title{
Waveform and Spectral Analyses of the 2011 Japan Tsunami Records on Tide Gauge and DART Stations Across the Pacific Ocean
}

\author{
Mohammad Heidarzadeh ${ }^{1,2}$ and Kenji Satake $^{2}$
}

\begin{abstract}
We studied the 11 March 2011 Tohoku tsunami through analysis of the sea level records from 21 tide gauge and 16 DART (Deep-ocean Assessment and Reporting of Tsunamis) stations from across the Pacific Ocean. The extreme power of this trans-oceanic tsunami was indicated by the trough-to-crest heights of $3.03 \mathrm{~m}$ at Arena Cove on the western coast of the USA and $3.94 \mathrm{~m}$ at Coquimbo on the southern coast of Chile. The average value of the maximum amplitude was $163.9 \mathrm{~cm}$ for the examined tide gauge records. At many coastal tide gauge stations the largest wave arrived several hours after the first arrival of the tsunami wave, and the tsunami lasted for a long time with an average duration of 4 days. On the contrary, at most of the DART stations in the deep ocean, the first wave was the largest, the tsunami amplitudes were smaller with an average maximum of $51.2 \mathrm{~cm}$, and the durations were shorter with an average of 2 days. The two dominant tsunami periods on the DART records were 37 and $67.4 \mathrm{~min}$, which are possibly attributed to the width and length of the tsunami source fault, respectively. The dimensions of the tsunami source was estimated as $233 \mathrm{~km} \times 424 \mathrm{~km}$. Wavelet analyses of tide gauge and DART records showed that most of the tsunami energy was distributed at the wide period band of around 10-80 min during the first hour after the tsunami arrival, then it was concentrated in a relatively narrower band. The frequency-time plots showed the switches and lapses of tsunami energy at the 35and 65-min period bands.
\end{abstract}

Key words: 2011 Tohoku tsunami, tide gauge data, DART stations, wavelet analysis, spectral analysis, numerical modeling, tsunami energy.

\section{Introduction}

On 11 March 2011 at 5:46:24 GMT (14:46:24 Japan local time) (USGS 2011) a giant earthquake occurred offshore of northeastern Japan rupturing

1 Faculty of Civil and Environmental Engineering, Tarbiat Modares University, Chamran Highway, Pol-e-Gisha, P.O.Box: 14115-397, Tehran, Iran. E-mail: m.heidarzadeh@modares.ac.ir

2 Earthquake Research Institute (ERI), University of Tokyo, Tokyo, Japan. around $450 \mathrm{~km}$ of the Japan Trench (FuJII et al. 2011). The earthquake was followed by a mega-tsunami causing massive destruction and deaths along the Pacific coast of northern Japan. Post-tsunami field surveys showed that the Tohoku mega-tsunami severely damaged three prefectures of Miyagi, Fukushima, and Iwate and caused damage in other regions like Hokkaido, Aomori, Ibaraki and Chiba prefectures (ТАKAHASHI et al. 2011).

The parent earthquake of the tsunami was one of the largest ever-recorded in history ranking fourth after the Chilean earthquake of 1960 (Mw 9.5), the Alaskan earthquake of 1964 (Mw 9.2), and the recent Sumatra-Andaman earthquake of 2004 (Mw 9.1). The earthquake epicenter was at $38.297^{\circ} \mathrm{N}$ and $142.372^{\circ} \mathrm{E}$ (USGS 2011) (Fig. 1) having a depth of around $10 \mathrm{~km}$.

This mega-thrust earthquake occurring at a relatively shallow depth created the third trans-oceanic tsunami of the 21 st century after the 26 December 2004 tsunami in Indonesia and the 27 February 2010 tsunami in Chile. The 2011 large Tohoku tsunami caused a death toll of nearly 20,000 in Japan (FIRE and Disaster Management Agency of Japan 2011) and exported death and destruction to very far coasts; it caused one death in California (WFAA 2011) and another in Jayapura, Indonesia (AsiaOne 2011) at the distances of about 8,000 and $4,500 \mathrm{~km}$ from the tsunami source, respectively.

The goal of this research is to extract the characteristics of the 2011 Tohoku tsunami using tide gauge and DART (Deep-ocean Assessment and Reporting of Tsunamis) data. Tide gauge data were applied in the last decades to study different tsunamis worldwide. SATAKE and KanAmori (1991) proposed methods to estimate the spatial distribution of co-seismic slip on the fault plane using tsunami 


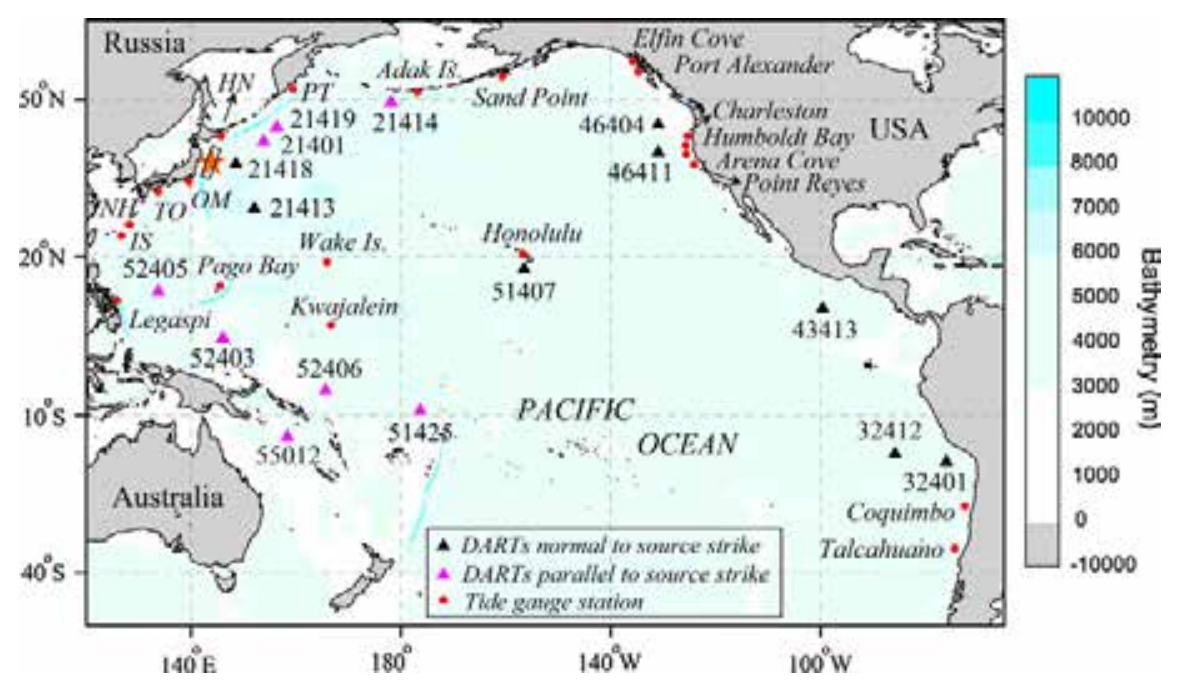

Figure 1

General location map of the Pacific Ocean showing the location of the great 2011 Tohoku earthquake (red asterisk), tide gauges (red points) and DART stations (black and pink triangles) used in this study. The rectangle is an approximation of the tsunami source and its strike angle. The details of the tide gauges and DART stations are given in Tables 1 and 2. HN Hanasaki, IS Ishigakijima, NH Naha, PT Petropavlovsk, $O M$ Omaezaki, and TO Tosashimizu

waveforms. RABINOVICH (1997) worked on the spectral analysis of tsunami waves and explained how to separate source and topography effects on tsunami mareograms. RABINOvich et al. (2006) studied the 2004 Sumatra tsunami using tide gauge data. KuLIKov et al. (1996) employed the tide gauge data to study the 1994 Skagway tsunami in Alaska. Development of digital ocean observation instruments in recent decades helped this method to play a more important role in tsunami research. In this context, the 2004 Indian Ocean tsunami can be regarded as a milestone because this tsunami was studied by several authors through analysis of the tide gauge and DART records from different regions around the world (e.g., TITOV et al. 2005; RabinOvich et al. 2006; Joseph et al. 2006; Dragani et al. 2006; FujI and Satake 2007). The DART stations are installed offshore in the deep water with the main goal to provide more refined information about the tsunami source because the information provided through tide gauge or seismic stations are not precise enough in this context. The DART system was developed at the National Oceanic and Atmospheric Administration (NOAA) of the Unite States and was deployed first offshore the US Pacific Coast in the 1990s (BERNARD et al. 2001). It has to be mentioned that while digital instruments have provided a great improvement in tsunami research in the recent decade, this was possible through setting the sampling rates of these instruments adequate to tsunamis, e.g., a sampling interval of $5 \mathrm{~min}$ or less, which was not always the case outside of the Pacific Ocean, e.g., in the Mediterranean Sea. However, after the 2004 Indian Ocean tsunami, this shortcoming has been improved almost everywhere in the world and old tsunamis have also been studied using the available historical analog records.

Here, we analyze the sea level data from a relatively large number of tide gauge and DART stations from across the Pacific basin to study the 2011 Tohoku earthquake. The main goals are: (1) to determine the statistical characteristics of the 2011 Tohoku tsunami as recorded at different locations across the Pacific Ocean, (2) to calculate the spectral characteristics of the tsunami wave in different locations, (3) to estimate the dimensions of the source fault using the spectral analysis, and (4) to study the energy behavior of tsunami using frequency-time (wavelet) analysis.

\section{Data}

Sea level records for 37 stations consisting of 21 tide gauge and 16 DART stations located across the Pacific Ocean were collected and then analyzed in 
this study (Fig. 1). The criterion for selecting these stations was to cover the whole Pacific Ocean. The tide gauge dataset includes five gauges along the Japanese coast, nine gauges along the USA west coast, two gauges along the Chilean coast, one gauge along the coast of the Philippines, one gauge on the Russian coast, and three on the Pacific Islands of Guam, Wake Island, and Kwajalein. The DART stations are distributed from the east to the west and from the north to the south of the Pacific Basin. The data were made available through different institutions and agencies consisting of: Japan Coast Guard (JCG 2011); USA National Oceanographic and Atmospheric Administration (NOAA 2011); and UNESCO Intergovernmental Oceanographic Commission (Ioc 2011).

The detailed information of the tide gauge and DART stations are summarized in Tables 1 and 2, respectively. The sampling interval for all tide gauge and DART data used here is $1 \mathrm{~min}$ allowing us to easily detect tsunami waves. All of the data used in this study are digital. In Tables 1-2, the direct distances of the sea level stations from the tsunami source are calculated.

\section{Waveform Analysis}

The method used in this study for data processing and analysis includes the following steps: (1) quality control, (2) removing low-frequency tides (high-pass filtering), (3) tsunami detection and statistical analysis, (4) spectral analysis, and (5) wavelet analysis (frequency-time analysis). This method is almost similar to the one used by RABINOvich and THOMSON (2007).

Using steps 1 and 2, the data will be ready for further analyses and thus these two steps are known as the data preparation efforts. The Butterworth IIR digital filter (MATHWorks 2012) was used in this study to remove low frequency signals (e.g., tides) for which a cut-off frequency of $0.000035 \mathrm{~Hz}$ (about $8 \mathrm{~h}$ ) was chosen. Figures 2 and 3 present the original and filtered signals for the 37 tide gauge and DART data used in this study, respectively. As can be seen in Figs. 2-3, the tsunami signal is clear enough in all of the stations and the first tsunami arrival can be distinguished easily in each station. It is evident that the clarity of the tsunami signals will facilitate further analyses of the data.

To study the general propagation pattern of tsunami waves across the Pacific Basin, we performed a numerical modeling for the waves generated by the 11 March 2011 Tohoku earthquake. As the initial condition for the tsunami propagation, we apply a simplified version of the source model proposed by FuJII et al. (2011) consisting of two straight faults. Table 3 summarizes the fault parameters of the tsunami source. The analytical formulas by OKADA (1985) are employed to calculate the seafloor deformation due to the parent earthquake using the seismic parameters presented in Table 3. The sea floor deformation due to the 11 March 2011 earthquake is shown in Fig. 4a which will be used as the initial condition for tsunami propagation modeling. The 5-min bathymetry grid provided through the GEBCO digital atlas was used here for numerical modeling of tsunami (Ioc et al. 2003). To examine the performance of the tsunami source (Table 3 ) in reproducing the actual tsunami, we compare the observed time histories of the 11 March 2011 tsunami in four DART stations (DARTs 21413, 21419, 21401 and 21418; see Fig. 1 for their locations) with simulated ones. Figure $4 \mathrm{~b}$ presents this comparison which shows that the simulated waves are in approximate agreement with the observed waves. Although the agreement between the simulated and observed waves is not as good as the one reported in FUJII et al. (2011), it seems to be enough for this study because the aim of this study is to investigate the general propagation pattern of the 2011 tsunami across the Pacific Ocean. Figure $4 \mathrm{c}$ shows the maximum tsunami wave height in each computational grid point during the whole simulation time which is an ideal representative of the pattern of tsunami energy distribution. According to Fig. 4c, most of the 2011 tsunami energy is directed towards the west coast of the USA and Chile. However, this result is not new as it was previously reported by SATAKE (1988) through studying the effect of bathymetry on tsunami propagation. SATAKE (1988) found that tsunamis generated offshore of Japan will cause large effects on the west coast of the USA and Chile. Snapshots of tsunami propagation at times $2,6,10,14,18$ and $22 \mathrm{~h}$ after the earthquake are shown in Fig. 4 d. 
Table 1

The tide gauges used in this study

\begin{tabular}{|c|c|c|c|c|c|c|}
\hline No. & Sea level station & Country (state) & Longitude & Latitude & $\begin{array}{l}\text { Distance to } \\
\text { the source }(\mathrm{km})\end{array}$ & $\begin{array}{l}\text { Signal/noise } \\
\text { ratio }\end{array}$ \\
\hline 1 & Hanasaki & Japan (Hokkaido) & $145.57^{\circ} \mathrm{E}$ & $43.28^{\circ} \mathrm{N}$ & 0,650 & 20 \\
\hline 2 & Omaezaki & Japan (Shizouka-ken) & $138.23^{\circ} \mathrm{E}$ & $34.60^{\circ} \mathrm{N}$ & 0,670 & 16 \\
\hline 3 & Tosashimizu & Japan (Kochi-ken) & $132.97^{\circ} \mathrm{E}$ & $32.78^{\circ} \mathrm{N}$ & 1,280 & 14 \\
\hline 4 & Naha & Japan (Okinawa) & $127.67^{\circ} \mathrm{E}$ & $26.22^{\circ} \mathrm{N}$ & 2,070 & 11 \\
\hline 5 & Petropavlovsk & Russia (Kamchatka) & $158.65^{\circ} \mathrm{E}$ & $53.02^{\circ} \mathrm{N}$ & 2,140 & 5 \\
\hline 6 & Ishigakijima & Japan (Okinawa) & $124.10^{\circ} \mathrm{E}$ & $24.20^{\circ} \mathrm{N}$ & 2,490 & 9 \\
\hline 7 & Pago Bay & USA (Guam Island) & $144.80^{\circ} \mathrm{E}$ & $13.43^{\circ} \mathrm{N}$ & 2,880 & 7 \\
\hline 8 & Wake Island & USA (Wake Island) & $166.62^{\circ} \mathrm{E}$ & $19.29^{\circ} \mathrm{N}$ & 3,090 & 5 \\
\hline 9 & Legaspi & Philippines (Albay) & $123.76^{\circ} \mathrm{E}$ & $13.15^{\circ} \mathrm{N}$ & 3,555 & 7 \\
\hline 10 & Adak Island & USA (Alaska) & $176.67^{\circ} \mathrm{W}$ & $51.83^{\circ} \mathrm{N}$ & 3,620 & 13 \\
\hline 11 & Kwajalein & Marshall Islands & $167.74^{\circ} \mathrm{E}$ & $08.74^{\circ} \mathrm{N}$ & 4,260 & 6 \\
\hline 12 & Sand point & USA (Alaska) & $160.48^{\circ} \mathrm{W}$ & $55.32^{\circ} \mathrm{N}$ & 4,780 & 8 \\
\hline 13 & Honolulu & USA (Hawaii) & $157.87^{\circ} \mathrm{W}$ & $21.30^{\circ} \mathrm{N}$ & 6,182 & 13 \\
\hline 14 & Elfin cove & USA (Alaska) & $136.33^{\circ} \mathrm{W}$ & $58.20^{\circ} \mathrm{N}$ & 6,265 & 9 \\
\hline 15 & Port Alexander & USA (Alaska) & $134.62^{\circ} \mathrm{W}$ & $56.25^{\circ} \mathrm{N}$ & 6,420 & 8 \\
\hline 16 & Charleston & USA (Oregon) & $124.33^{\circ} \mathrm{W}$ & $43.33^{\circ} \mathrm{N}$ & 7,770 & 8 \\
\hline 17 & Humboldt Bay & USA (California) & $124.13^{\circ} \mathrm{W}$ & $40.82^{\circ} \mathrm{N}$ & 7,935 & 4 \\
\hline 18 & Arena Cove & USA (California) & $123.73^{\circ} \mathrm{W}$ & $38.95^{\circ} \mathrm{N}$ & 8,085 & 9 \\
\hline 19 & Point Reyes & USA (California) & $123.00^{\circ} \mathrm{W}$ & $38.00^{\circ} \mathrm{N}$ & 8,190 & 8 \\
\hline 20 & Coquimbo & Chile (Region de Coquimbo) & $071.34^{\circ} \mathrm{W}$ & $29.95^{\circ} \mathrm{S}$ & 17,500 & 11 \\
\hline 21 & Talcahuano & Chile (Region de Biobio) & $073.11^{\circ} \mathrm{W}$ & $36.70^{\circ} \mathrm{S}$ & 17,750 & 13 \\
\hline
\end{tabular}

In the following, the details of the methods used for statistical, spectral and wavelet analysis in this study will be given.

\subsection{Statistical Analysis}

The statistical characteristics used here to study the 2011 Tohoku tsunami are:

1. The arrival time of the first tsunami wave in each station,

2. The sign of the first wave arriving in each station (either elevation or depression wave),

3. The arrival time of the maximum wave in each station,

4. The maximum trough-to-crest wave height recorded in each station,

5. The number of the maximum wave, i.e., which wave was the largest wave, and

6. The duration of tsunami wave oscillations.

The above statistical properties of the tsunami will be calculated by a visual look at the final filtered signal (i.e., Figs. 2, 3).

\subsection{Spectral Analysis}

The spectral analysis here was performed using Welch's averaged modified periodogram method of spectral estimation considering Hamming window and overlaps (Welch 1967). The Welch's method splits the data into overlapping segments, computes modified periodograms of the overlapping segments, and averages the resulting periodograms to produce the power spectral density estimate (OPPENHEIM and SCHAFER 1975).

For a discrete input signal of $x\left(t_{n}\right)$, in which $t_{n}$ is the time in seconds and $n=0,1,2,3 \ldots, N-1(N$ is the total number of time and frequency samples), the Discrete Fourier Transform (DFT) may be calculated using the following equation (OPPENHEIM and SCHAFER 1975):

$$
\operatorname{DFT}\left(f_{k}\right)=\sum_{n=0}^{N-1} x\left(t_{n}\right) e^{-j f_{k} t_{n}} .
$$

Where DFT $\left(f_{k}\right)$ is the Discrete Fourier Transform of the input signal $x(t)$ at the frequency of $f_{k}(k=0,1,2,3 \ldots, N-1), j$ is the imaginary unit, $e$ is the Napier's constant, and $t_{n}=n T$ ( $T$ is the 
Table 2

The DART stations used in this study

\begin{tabular}{|c|c|c|c|c|c|}
\hline No. & DART name & Location & Longitude & Latitude & $\begin{array}{l}\text { Distance to the } \\
\text { source }(\mathrm{km})\end{array}$ \\
\hline 1 & 21418 & NE Tokyo & $148.69^{\circ} \mathrm{E}$ & $38.71^{\circ} \mathrm{N}$ & 623 \\
\hline 2 & 21401 & Iturup Island & $152.58^{\circ} \mathrm{E}$ & $42.62^{\circ} \mathrm{N}$ & 1,171 \\
\hline 3 & 21419 & SE Kuril Island & $155.74^{\circ} \mathrm{E}$ & $44.46^{\circ} \mathrm{N}$ & 1,579 \\
\hline 4 & 21413 & SE Tokyo & $152.12^{\circ} \mathrm{E}$ & $30.52^{\circ} \mathrm{N}$ & 1,307 \\
\hline 5 & 52405 & Guam (W Pacific) & $132.33^{\circ} \mathrm{E}$ & $12.88^{\circ} \mathrm{N}$ & 3,058 \\
\hline 6 & 52403 & Truk (W Pacific) & $145.59^{\circ} \mathrm{E}$ & $04.05^{\circ} \mathrm{N}$ & 3,850 \\
\hline 7 & 21414 & NW Pacific Ocean & $178.26^{\circ} \mathrm{E}$ & $48.95^{\circ} \mathrm{N}$ & 4,107 \\
\hline 8 & 52406 & Guadalcanal & $165.00^{\circ} \mathrm{E}$ & $05.29^{\circ} \mathrm{S}$ & 5,420 \\
\hline 9 & 55012 & NE Australia & $158.40^{\circ} \mathrm{E}$ & $15.80^{\circ} \mathrm{S}$ & 6,249 \\
\hline 10 & 51425 & Samoa & $176.24^{\circ} \mathrm{W}$ & $09.51^{\circ} \mathrm{S}$ & 6,984 \\
\hline 11 & 51407 & SE Honolulu & $156.59^{\circ} \mathrm{W}$ & $19.59^{\circ} \mathrm{N}$ & 7,039 \\
\hline 12 & 46404 & Astoria, Oregon & $128.77^{\circ} \mathrm{W}$ & $45.86^{\circ} \mathrm{N}$ & 9,877 \\
\hline 13 & 46411 & San Francisco & $127.02^{\circ} \mathrm{W}$ & $39.35^{\circ} \mathrm{N}$ & 10,035 \\
\hline 14 & 43413 & Acapulco, Mexico & $099.85^{\circ} \mathrm{W}$ & $11.07^{\circ} \mathrm{N}$ & 13,411 \\
\hline 15 & 32412 & Lima, Peru & $086.39^{\circ} \mathrm{W}$ & $17.98^{\circ} \mathrm{S}$ & 15,859 \\
\hline 16 & 32401 & Arica, Chile & $074.75^{\circ} \mathrm{W}$ & $19.30^{\circ} \mathrm{S}$ & 17,116 \\
\hline
\end{tabular}

sampling interval in seconds). In the Welch method, the signal $x(t)$ will be divided into successive blocks, and then the squared-magnitude of the DFT $\left(f_{k}\right)$ will be averaged for each signal block. Suppose that the signal $x(t)$ is already divided into $M$ blocks. Then, each block within this signal will be obtained using the following equation:

$$
x_{m}(n)=x(n+m N),
$$

where $m=1,2,3 \ldots, M$ ( $M$ is the total number of signal blocks). Finally, the Welch modified periodogram $\left[S_{x}\left(f_{k}\right)\right]$ will be calculated as below:

$$
S_{x}\left(f_{k}\right)=\frac{1}{M} \sum_{m=0}^{M-1}\left|D F T_{k}\left(x_{m}\right)\right|^{2} .
$$

The main advantage of the Welch's method over the standard periodogram method is that it reduces noise in the estimated power spectra (OPPENHEIM and SCHAFER 1975). Here, we apply the Welch algorithm in the Matlab program for our spectral analysis (MathWorks 2012). The average length of the tsunami signal used for spectral analysis is about 1,690 data points which means a time length of around $28 \mathrm{~h}$. The hamming window method was used in this study for spectral analysis, whose length was 500 data points, i.e., a time length of about $8 \mathrm{~h}$. The windows were overlapped using 200 data points (i.e., a time length of $3.33 \mathrm{~h}$ ).

\subsection{Wavelet Analysis}

Although the spectral analysis using the above method is a powerful tool in discovering the existing signals and peak periods in a sea level record, it does not give the timing of each peak period. For example, in a 3-day-long tsunami record, it is not known that when each peak occurs. The information about the timing of each peak period is important in understanding the physics of the phenomenon under study and, hence, efforts were made to add timing to the traditional spectral analysis. Possibly the simplest way to address this problem was the application of the windowed Fourier transform in which the whole time series is divided into some overlapping segments and then the Fourier transform is applied on each segment. The square modulus of the windowed Fourier transform is known as the Spectrogram. Although the Spectrogram method is of significant help for studying time-dependent phenomena like storms, hurricanes and tsunamis, this technique is biased to window length and thus making it inefficient (KAISER 1994).

Based on the above explanations, in fact, the wavelet method is an advanced technique compared to the Spectrogram method lacking the aforesaid shortcoming. The two main advantages of the wavelet analysis are: (1) employing a window width which is a function of frequency and thus the window length is not fixed and, (2) applying a function composed of 

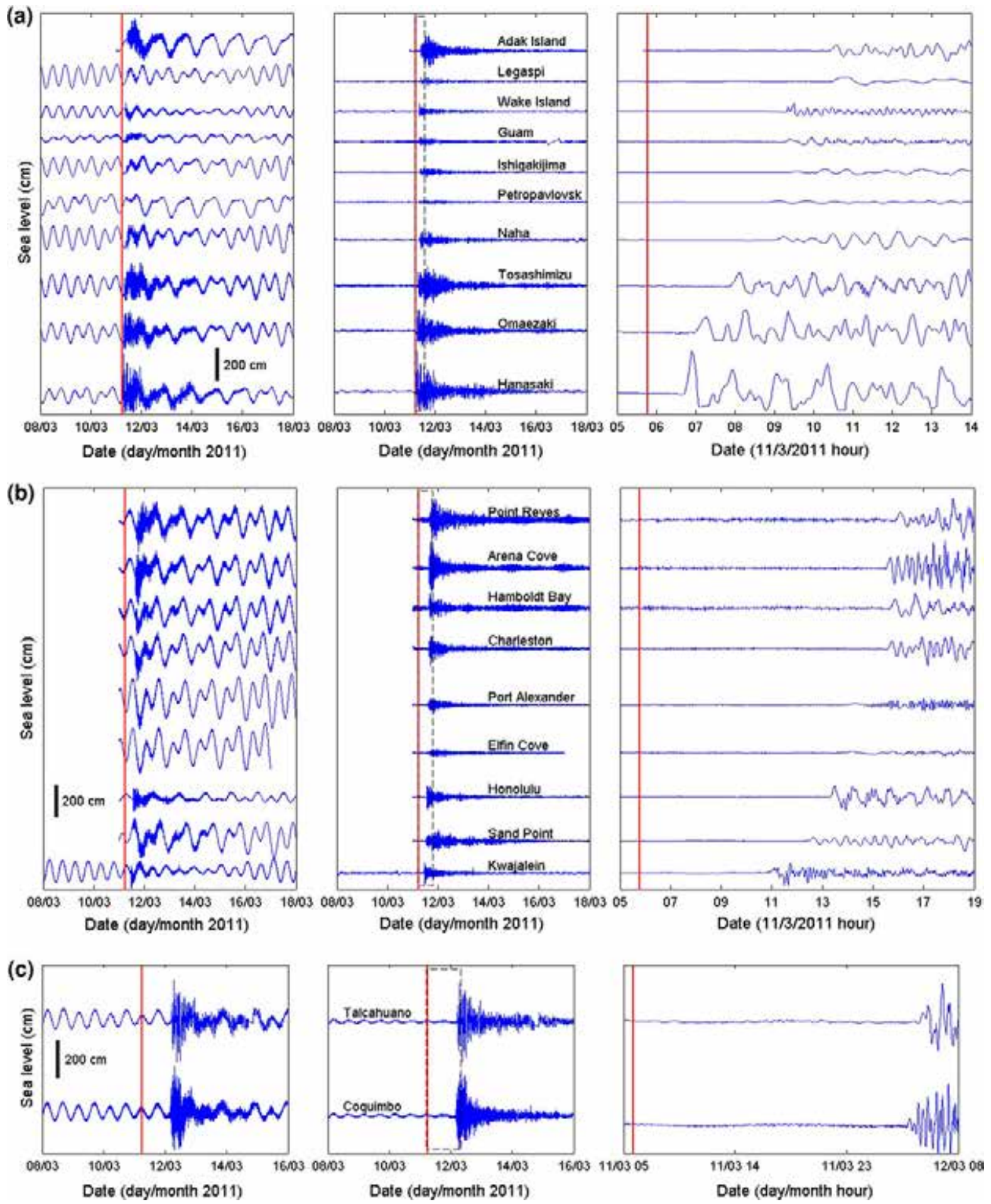

Figure 2

The original and filtered tsunami signals recorded on different tide gauges across the Pacific Ocean. The red-vertical line represents the time of the earthquake. The dashed rectangle shows part of the waveform enlarged in the right panel 

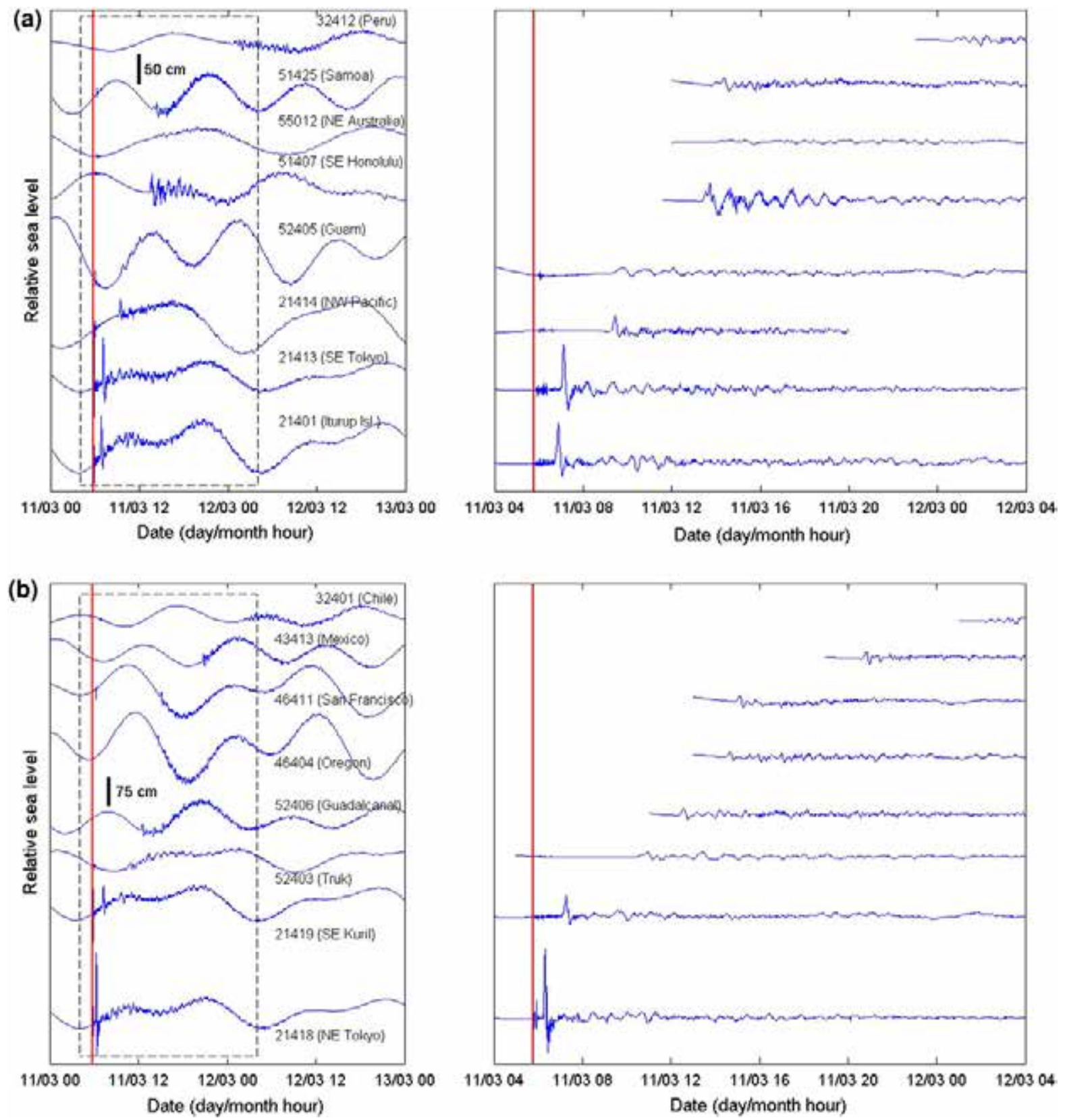

Figure 3

The original and filtered tsunami signals recorded on different DART stations across the Pacific Ocean. The red-vertical line represents the time of the earthquake. The dashed rectangle shows part of the waveform enlarged in the right panel

a complex exponential equation modulated by a Gaussian function for its fitting procedure which is usually known as the mother function.

One of the famous wavelet mother functions is the Morlet function $[\psi(t)]$ which is given by the following equation (GoupILLAud et al. 1984):

$$
\begin{aligned}
\psi(t)= & \pi^{-1 / 4} e^{-1 / 2 t^{2}}\left(1+e^{-f_{0}^{2}}-2 e^{-3 / 4 f_{0}^{2}}\right)^{-1 / 2} \\
& \times\left(e^{j f_{0} t}-e^{-1 / 2 f_{0}^{2}}\right)
\end{aligned}
$$

in which, $f_{0}$ is the central frequency of the wavelet function, and $t$ is time. The Morlet wavelet mother 
Table 3

Tectonic parameters of the March 2011 tsunami source used in this study (a simplified version of the source by FUJII et al. 2011)

\begin{tabular}{|c|c|c|c|c|c|c|c|c|c|c|}
\hline \multirow[t]{2}{*}{ Segment } & \multicolumn{2}{|c|}{ Fault start point } & \multicolumn{2}{|c|}{ Fault end point } & \multirow[t]{2}{*}{ Width (km) } & \multirow[t]{2}{*}{ Displacement (m) } & \multirow[t]{2}{*}{ Depth $(\mathrm{km})$} & \multirow[t]{2}{*}{ Dip $\left(^{\circ}\right)$} & \multirow[t]{2}{*}{ Slip $\left(^{\circ}\right)$} & \multirow[t]{2}{*}{ Strike $\left(^{\circ}\right)$} \\
\hline & Lon. $^{\text {a }}\left({ }^{\circ} \mathrm{E}\right)$ & Lat. ${ }^{\mathrm{b}}\left({ }^{\mathrm{o}} \mathrm{N}\right)$ & Lon. $\left({ }^{\circ} \mathrm{E}\right)$ & Lat. $\left({ }^{\mathrm{o}} \mathrm{N}\right)$ & & & & & & \\
\hline 1 & 145.2 & 40.7 & 144.3 & 36.7 & 100 & 20 & 6 & 12 & 81 & 200 \\
\hline 2 & 143.5 & 39.0 & 143.1 & 37.5 & 50 & 15 & 6 & 12 & 81 & 200 \\
\hline
\end{tabular}

a Longitude

b Latitude

function is used in this study for our wavelet analysis. Here, we apply the wavelet analysis package developed by ToRrence and Compo (1998).

\section{Results of the Analyses}

\subsection{Statistical Properties}

Tables 4-5 present the statistical characteristics of the sea level oscillations caused by the 11 March 2011 Tohoku tsunami on different tide gauge and DART stations across the Pacific Ocean. Comparison between the physical properties of the tsunami waves in different stations and between tide gauge and DART stations yields useful information about the tsunami behavior in the Pacific Basin.

Among the analyzed stations, Hanasaki and Talcahuano were the first and the last stations receiving the tsunami wave, respectively (Tables 4-5/ Column 3). The tsunami signal arrived at Hanasaki around an hour after the earthquake whereas it took almost 1 day for tsunami waves to reach the Talcahuano station in Chile. In all of the stations, the first wave was a leading elevation one (Tables 4-5/Column 5).

According to Table 4, the arrival time of the maximum wave is far longer than that of the first wave for the tide gauge stations. For example, the maximum tsunami wave arrived in Tosashimizu at 16:55 GMT on 11 March after $11 \mathrm{~h}$ and 9 min from the time of the earthquake occurrence whereas the first wave arrived about $2 \mathrm{~h}$ after the earthquake in this station. For all of the examined tide gauge stations with a few exceptions (Hanasaki, Legaspi and Honolulu), the maximum wave was not the first wave but mostly occurred several hours after (Table 4/column 7). The largest waves in Naha and
Sand Point were the 6th and the 28th ones, respectively. A surprise in this context is the Sand Point station in which the largest wave arrived more than $12 \mathrm{~h}$ after the arrival of the first wave.

The tremendous power of the 2011 Tohoku tsunami can be evidenced by Table 4/column 8 where the maximum trough-to-crest amplitude of the tsunami signal is presented. It is more than $200 \mathrm{~cm}$ at almost half of the analyzed tide gauge stations. The maximum trough-to-crest amplitude is more than $300 \mathrm{~cm}$ at four of the examined tide gauge stations. The average value for the maximum troughto-crest amplitude of the tsunami is $163.9 \mathrm{~cm}$ for the 21 tide gauge stations. At some stations at the west coast of the USA, this parameter is around $150 \mathrm{~cm}$. The maximum trough-to-crest amplitude is $394 \mathrm{~cm}$ recorded at the Coquimbo tide gauge station in Chile at the distance of about $17,500 \mathrm{~km}$ from the tsunami source. As discussed earlier, observation of relatively large wave amplitudes in Chile can be attributed to the bathymetric (SATAKE 1988) and directivity (Ben-Menahem and Rosenman 1972) effects on the propagation of tsunami waves in the far-field as it was evidenced by our basin-wide numerical modeling of tsunami too (Fig. 4c).

An important characteristic of the tsunami signals shown in Fig. 2 is their relatively long duration. The duration of tsunami waves is calculated and is shown in Table 4/last column. For calculation of the tsunami duration in each station, the time interval between tsunami arrival and reaching the sea-level oscillation to that before tsunami arrival was selected as the tsunami duration time. It can be seen that the tsunami waves are lasting for several days in most of the analyzed tide gauge stations (Fig. 2 and Table 4). The average duration of tsunami wave for the tide gauge stations is 4 days (Table 4). This long duration 

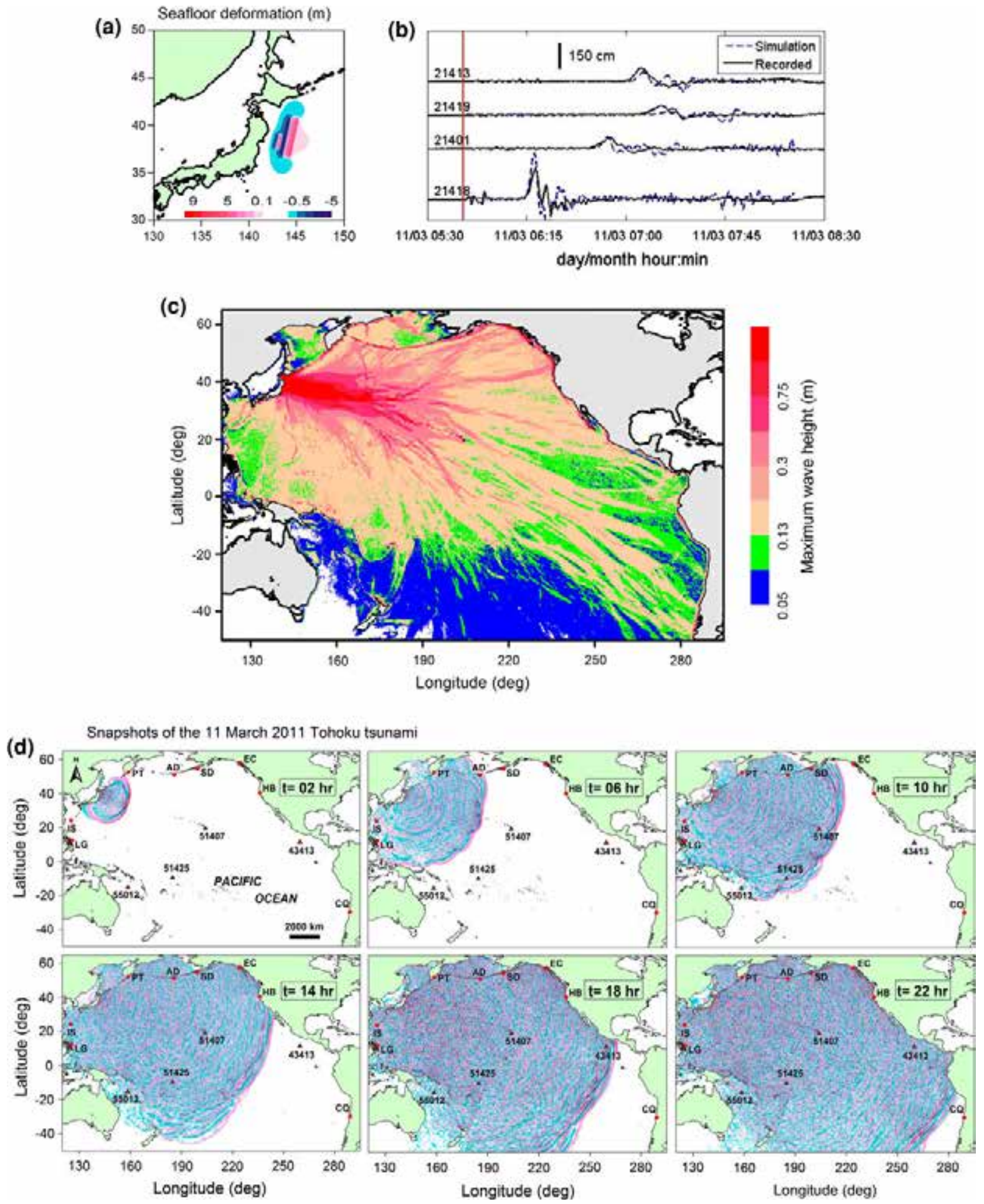

Figure 4

a The tsunami source used in this study, $\mathbf{b}$ comparison between observed and simulated waveforms in some DART stations, $\mathbf{c}$ the distribution of the maximum tsunami wave heights, and d snapshots of tsunami simulations at different times. $L G$ Legaspi, IS Ishigakijima, $P T$ Petropavlovsk, $A D$ Adak Island, $S D$ Sand Point, $E C$ Elfin Cove, $H B$ Humboldt Bay, $C Q$ Coquimbo 
Table 4

Statistical analysis of the tide-gauge records

\begin{tabular}{|c|c|c|c|c|c|c|c|c|c|}
\hline \multirow[t]{2}{*}{ No. } & \multirow{2}{*}{$\begin{array}{l}\text { Sea level } \\
\text { station }\end{array}$} & \multicolumn{3}{|l|}{ First wave } & \multicolumn{4}{|l|}{ Maximum wave } & \multirow{2}{*}{$\begin{array}{l}\text { Duratior } \\
\text { (day) }\end{array}$} \\
\hline & & $\begin{array}{l}\text { Arrival time } \\
\text { (GMT) } \\
\text { (dd/mm-HH:MM) }\end{array}$ & $\begin{array}{l}\text { Travel } \\
\text { time }^{\mathrm{a}} \\
\text { (h:min) }\end{array}$ & $\operatorname{Sign}^{\mathrm{b}}$ & $\begin{array}{l}\text { Arrival time } \\
\text { (GMT) } \\
(\mathrm{dd} / \mathrm{mm}-\mathrm{HH}: \mathrm{MM})\end{array}$ & $\begin{array}{l}\text { Travel } \\
\text { time }^{\mathrm{a}} \\
\text { (h:min) }\end{array}$ & $\begin{array}{l}\text { Observed max. } \\
\text { wave height } \\
(\mathrm{cm})^{\mathrm{c}}\end{array}$ & $\begin{array}{l}\text { No. of the } \\
\text { max. wave }\end{array}$ & \\
\hline 1 & Hanasaki & 11/03-06:42 & $00: 54$ & $(+)$ & 11/03-06:54 & 01:08 & 369 & 1 & 4.4 \\
\hline 2 & Omaezaki & 11/03-06:59 & $01: 13$ & $(+)$ & 11/03-08:15 & $02: 29$ & 206 & 3 & 3.3 \\
\hline 3 & Tosashimizu & $11 / 03-07: 53$ & 02:07 & $(+)$ & $11 / 03-16: 55$ & 11:09 & 201 & 24 & 3.6 \\
\hline 4 & Naha & 11/03-09:05 & 03:19 & $(+)$ & 11/03-12:09 & $06: 23$ & 116 & 6 & 3.3 \\
\hline 5 & Petropavlovsk & $11 / 03-08: 53$ & 03:07 & $(+)$ & $11 / 03-16: 21$ & $10: 35$ & 19 & 15 & 3.4 \\
\hline 6 & Ishigakijima & 11/03-09:23 & $03: 37$ & $(+)$ & $11 / 03-12: 45$ & $06: 59$ & 40 & 6 & 3.9 \\
\hline 7 & Pago bay & 11/03-09:17 & 03:31 & $(+)$ & 11/03-09:57 & $04: 11$ & 51 & 2 & 2.0 \\
\hline 8 & Wake Island & 11/03-09:19 & $03: 33$ & $(+)$ & 11/03-09:29 & $03: 43$ & 76 & 2 & 2.6 \\
\hline 9 & Legaspi & 11/03-10:29 & $04: 43$ & $(+)$ & 11/03-10:50 & $05: 04$ & 49 & 1 & 4.3 \\
\hline 10 & Adak Island & $11 / 03-10: 25$ & $04: 39$ & $(+)$ & $11 / 03-17: 53$ & $12: 07$ & 191 & 20 & 3.5 \\
\hline 11 & Kwajalein & $11 / 03-10: 52$ & $05: 06$ & $(+)$ & $11 / 03-11: 44$ & $05: 58$ & 140 & 3 & 2.4 \\
\hline 12 & Sand Point & $11 / 03-12: 30$ & $06: 44$ & $(+)$ & $12 / 03-00: 49$ & $19: 03$ & 99 & 28 & 4.6 \\
\hline 13 & Honolulu & $11 / 03-13: 19$ & $07: 33$ & $(+)$ & $11 / 03-13: 29$ & $07: 43$ & 134 & 1 & 3.3 \\
\hline 14 & Elfin Cove & $11 / 03-13: 59$ & $08: 13$ & $(+)$ & $11 / 03-22: 37$ & $16: 51$ & 46 & 37 & 3.5 \\
\hline 15 & Port Alexander & 11/03-14:09 & $08: 23$ & $(+)$ & 11/03-19:17 & $13: 31$ & 80 & 41 & 4.0 \\
\hline 16 & Charleston & $11 / 03-15: 37$ & $09: 51$ & $(+)$ & $11 / 03-16: 56$ & $11: 10$ & 165 & 5 & 5.7 \\
\hline 17 & Humboldt Bay & $11 / 03-15: 41$ & 09:55 & $(+)$ & $11 / 03-16: 40$ & $10: 54$ & 157 & 3 & 6.0 \\
\hline 18 & Arena Cove & $11 / 03-15: 32$ & $09: 46$ & $(+)$ & $11 / 03-17: 50$ & 12:04 & 303 & 9 & 6.0 \\
\hline 19 & Point Reyes & $11 / 03-15: 56$ & $10: 10$ & $(+)$ & 11/03-18:10 & $12: 24$ & 257 & 7 & 6.0 \\
\hline 20 & Coquimbo & $12 / 03-03: 56$ & $22: 10$ & $(+)$ & $12 / 03-07: 12$ & $25: 26$ & 394 & 8 & 3.4 \\
\hline 21 & Talcahuano & $12 / 03-04: 50$ & 23:04 & $(+)$ & $12 / 03-06: 44$ & $24: 58$ & 349 & 3 & 4.0 \\
\hline Average & & & & & & & 163.9 & 11 & 4.0 \\
\hline
\end{tabular}

a Compared to the earthquake time (11/03/2011 05:46':23" GMT)

b (-) and (+) represent leading depression and elevation waves, respectively

c Maximum trough-to-crest wave height

which also was observed during the 2004 Indian Ocean Tsunami (RABINOVICH et al. 2006), seems to be typical of large trans-oceanic tsunamis.

Table 5 presents the physical properties of the sea level oscillations recorded by DART stations. According to this table, noticeable differences can be seen between the statistical properties of tsunami waves recorded on tide gauge and DART stations. In sharp contrast to tide gauge stations, the first wave is the largest one at most of the DART stations. Out of the 16 DART stations, Table 5 shows that the first wave is the largest one at 11 of them. Except a few DART stations, the maximum trough-to-crest tsunami amplitude is less than $30 \mathrm{~cm}$ at most of the DART stations (Table 5). The average value of the maximum trough-to-crest tsunami amplitude is $51.2 \mathrm{~cm}$ for the examined DART stations which is more than three times less than that for the tide gauge stations (i.e., $163.9 \mathrm{~cm}$, Table 4). This is not surprising because tide gauge stations are deployed in the harbors with shallower depth whereas DART stations are installed offshore at larger water depth. Therefore, it is expected that tsunami amplitudes are larger on tide gauges due to the shoaling of tsunami waves in the shallow water area. Another significant difference between the behavior of tsunami oscillations on DART and tide gauge stations is about the duration of the tsunami oscillations. While the average duration of tsunami oscillations is 4 days in tide gauge stations (Table 4), it is 2 days in DART stations (Table 5). The longer oscillations of tsunami waves on tide gauge stations compared to that on DART stations is due to the location of tide gauges in the coastal areas which will be influenced by the effects of the continental shelf, coastal bathymetry, and harbors and bays on the incoming tsunami waves. 
Table 5

Statistical analysis of the DART records

\begin{tabular}{|c|c|c|c|c|c|c|c|c|c|}
\hline No. & $\begin{array}{l}\text { DART } \\
\text { name }\end{array}$ & $\begin{array}{l}\text { Arrival time (GMT) } \\
(\mathrm{dd} / \mathrm{mm} \text {-h:min) }\end{array}$ & $\begin{array}{l}\text { Travel time }{ }^{a} \\
\text { (h:min) }\end{array}$ & $\operatorname{Sign}^{\mathrm{b}}$ & $\begin{array}{l}\text { Max. wave } \\
\text { height }(\mathrm{cm})^{\mathrm{c}}\end{array}$ & $\begin{array}{l}\text { No. of the } \\
\text { max. wave }\end{array}$ & $\begin{array}{l}\text { Spectral peak } \\
(\min )(1)\end{array}$ & $\begin{array}{l}\text { Spectral Peak } \\
(\min )(2)\end{array}$ & $\begin{array}{l}\text { Duration } \\
\text { (day) }\end{array}$ \\
\hline 1 & 21418 & 11/03-06:14 & $00: 28$ & $(+)$ & 215.9 & 1 & 45 & 64 & 3.1 \\
\hline 2 & 21401 & 11/03-06:44 & $00: 58$ & $(+)$ & 92.7 & 1 & 28 & 59 & 2.6 \\
\hline 3 & 21419 & 11/03-07:07 & $01: 21$ & $(+)$ & 79.6 & 1 & 47 & 75 & 2.0 \\
\hline 4 & 21413 & 11/03-07:00 & $01: 14$ & $(+)$ & 113.1 & 1 & 33 & 69 & 2.7 \\
\hline 5 & 52405 & 11/03-09:31 & $03: 45$ & $(+)$ & 15.6 & 1 & 33 & 69 & 1.3 \\
\hline 6 & 52403 & 11/03-10:32 & $04: 46$ & $(+)$ & 22.5 & 5 & 41 & 64 & 1.4 \\
\hline 7 & 21414 & 11/03-09:18 & $03: 32$ & $(+)$ & 35.2 & 1 & 37 & 79 & 2.4 \\
\hline 8 & 52406 & $11 / 03-12: 25$ & $06: 39$ & $(+)$ & 29.3 & 1 & 33 & 69 & 2.2 \\
\hline 9 & 55012 & 11/03-14:31 & $08: 45$ & $(+)$ & 7.5 & 2 & 35 & 54 & 2.3 \\
\hline 10 & 51425 & $11 / 03-13: 53$ & 08:07 & $(+)$ & 23.6 & 1 & 36 & 76 & 2.2 \\
\hline 11 & 51407 & $11 / 03-13: 22$ & $07: 36$ & $(+)$ & 54.7 & 1 & 45 & 75 & 2.9 \\
\hline 12 & 46404 & 11/03-14:32 & $08: 46$ & $(+)$ & 27.0 & 6 & 34 & 60 & 1.5 \\
\hline 13 & 46411 & $11 / 03-14: 57$ & 09:11 & $(+)$ & 33.8 & 1 & 26 & 45 & 1.2 \\
\hline 14 & 43413 & 11/03-20:39 & $14: 53$ & $(+)$ & 34.2 & 1 & 33 & 62 & 1.0 \\
\hline 15 & 32412 & $12 / 03-00: 46$ & $19: 00$ & $(+)$ & 17.4 & 3 & 42 & 79 & 2.5 \\
\hline 16 & 32401 & $12 / 03-02: 20$ & $20: 34$ & $(+)$ & 17.5 & 4 & 44 & 79 & 1.6 \\
\hline Average & & & & & 51.2 & 2 & 37 & 67.4 & 2.0 \\
\hline
\end{tabular}

a Compared to the earthquake time (i.e., 11/03/2011 05:46':23" GMT)

b (-) and (+) represent leading depression and elevation waves, respectively

c Maximum trough-to-crest wave height

The DART stations are capable of recording seismic waves too, although this capability depends on the sampling interval of DART stations and the strength and duration of the seismic source. Normally, short sampling intervals (e.g., less than $0.01 \mathrm{~s}$ ) are necessary to record seismic waves whereas DART stations normally sample sea level oscillations with the intervals of $15 \mathrm{~s}, 1 \mathrm{~min}$ or larger. Therefore, if the strength and duration of the seismic source is large enough, the traces of the seismic oscillations will be found on the DART waveforms too. As the sampling interval of our DART data is $15 \mathrm{~s}$ for a short time after the earthquake, we are able to see the traces of seismic oscillations in our DART waveforms (Fig. 5). For relatively far stations from the earthquake source (e.g., station 51425), the arrival time difference between the seismic waves and the tsunami waves are longer than that for the closer stations to the source (e.g., station 21418).

\subsection{Main Spectral Peaks}

Since the aim of our spectral analysis is to determine the spectral characteristics of the tsunami source, the spectral analysis here is performed only for the DART data. The reason is that normally the spectra of coastal tide gauge stations are strongly influenced by topographic features, and hence it is difficult to extract tsunami source characteristics from their spectra.

The results of spectral analysis for 16 DART records are presented in Fig. 6 and Table 5. The two major spectral peaks are shown in Fig. 6 with asterisks which are the period bands of 35-45 min and 60-75 min. According to Table 5, the average values of the spectral peaks for all 16 DART stations are 37 and $67.4 \mathrm{~min}$. However, it should be mentioned that besides the mentioned two peaks, other peaks also exist in some of the spectra.

The spectral characteristics of tsunami waveforms are usually influenced by the location of the station relative to the tsunami source strike. For example, for a station located normal to the source strike, it is expected that the peak tsunami period is mainly dictated by the width of the tsunami source. In contrast, the spectra of the stations located along the source strike may be influenced by the length of the source fault. To study this effect, we have classified the DART stations into two groups for spectral analysis: (1) stations located nearly perpendicular to 


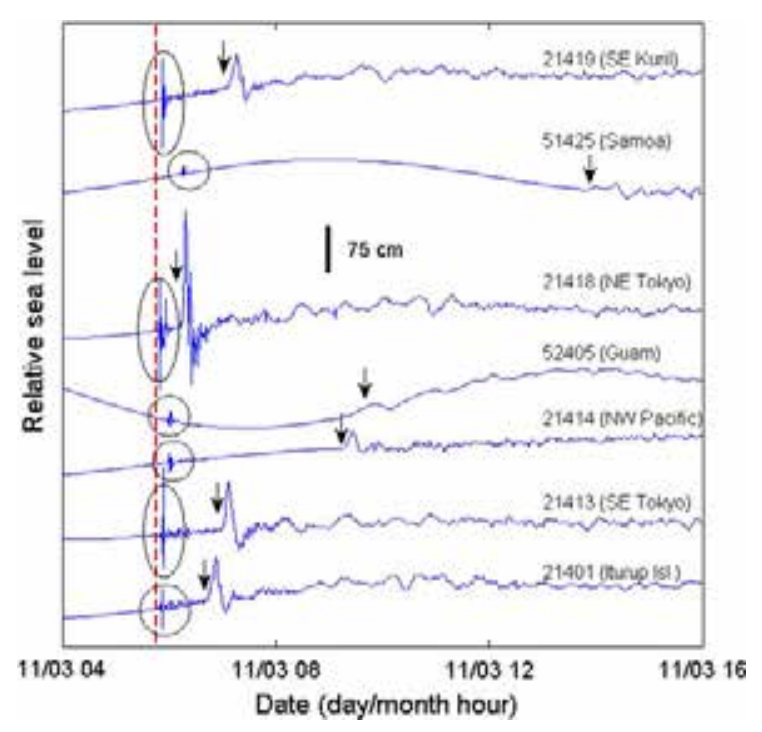

Figure 5

Traces of seismic oscillations in DART waveforms. Arrows show the first arrival of tsunami waves while the circles show seismic oscillations recorded on DART waveforms. The dashed vertical line represents the earthquake time

the tsunami source strike, e.g., DART 21413, (black triangles in Fig. 1, spectra in Fig. 6a) and (2) those located nearly along the source strike (i.e., lateral stations), e.g., DART 52405, (purple triangles in Fig. 1, spectra in Fig. 6b).

Based on Fig. 6a, the governing period band is 35-45 min for the DART stations located normal to the source strike. Almost all of the DART spectra in Fig. 6a show that the period band of 35-45 $\mathrm{min}$ is stronger than the other one. The only exception is DART 46411 in which the two peaks are almost of the same strength. This seems normal because this DART station is not located normal or parallel to the source strike (Fig. 1) but in the middle, and, hence, it is expected that the two peaks have the same strength at this DART station.

For the DART stations located parallel to the source strike (i.e., lateral stations), Fig. $6 \mathrm{~b}$ shows that the two peak periods are almost of the same strength. However, in the spectra of the DARTs 52405 and 52403 , the peak at $60-75 \mathrm{~min}$ is noticeably stronger. Based on the directivity effect (Ben-Menahem and Rosenman 1972), it has been long known that most of the tsunami energy travels perpendicular to the source strike which means that tsunami energy is mainly dictated by the width of the source (Fig. 4c). Therefore, it is expected that width of the tsunami source contributes strongly to the tsunami spectra whereas the length of the source has a relatively smaller contribution. Based on this, as the period band of 35-45 min is strong in both directions, we may attribute this period band to the width of the tsunami source. The other period band (i.e., 60-75 $\mathrm{min}$ ) is possibly associated with the length of the tsunami source. Additional evidence will be presented in the next section to support this finding.

\subsection{Timing of the Spectral Peaks}

Figure 7 present the results of wavelet analysis for some selected tide gauge and DART stations. Wavelet plots are also known as $f-t$ plots because they show how tsunami energy changes at different frequency bands $(f)$ by passing time $(t)$. The tsunami spectra shown in Fig. 7 are the global wavelet spectrum which is the time-averaged spectral energy over all times. Tsunami arrival is clear in all of the $f-t$ plots in Fig. 7 because the level of wave energy is much larger after the tsunami arrival than that before.

Similar to our spectral analysis, in all of the $f-t$ plots for the DART stations shown in Fig. 7, the two major peak period bands are 35-45 and 60-75 min. For the DART stations located near normal to the fault strike (Fig. 7a), most of the tsunami energy is occurring at the period band of 35-45 min whereas Fig. $7 \mathrm{~b}$ shows that for the lateral stations, it occurs at the period band of $60-75 \mathrm{~min}$. For the two DART stations of 52405 and 52403 which can be regarded as pure lateral stations, the $f-t$ plots shows that most of the tsunami energy is concentrated at the period band of 60-75 min (rectangles in Fig. 7b).

The temporal changes of tsunami energy can be seen in Fig. 7. For the three DART records of 21418 , 21413 and 21401 (Fig. 7a, b), the tsunami energy is distributed in a relatively wide period band of 10-80 min for the first $2 \mathrm{~h}$ after the tsunami arrival at these stations. This may show that the tsunami wave field is rather complicated and contains several signals with different amplitudes and wavelengths just after the tsunami generation which may be attributed to the slip heterogeneity at the tsunami source area. However, after some hours the energy is 

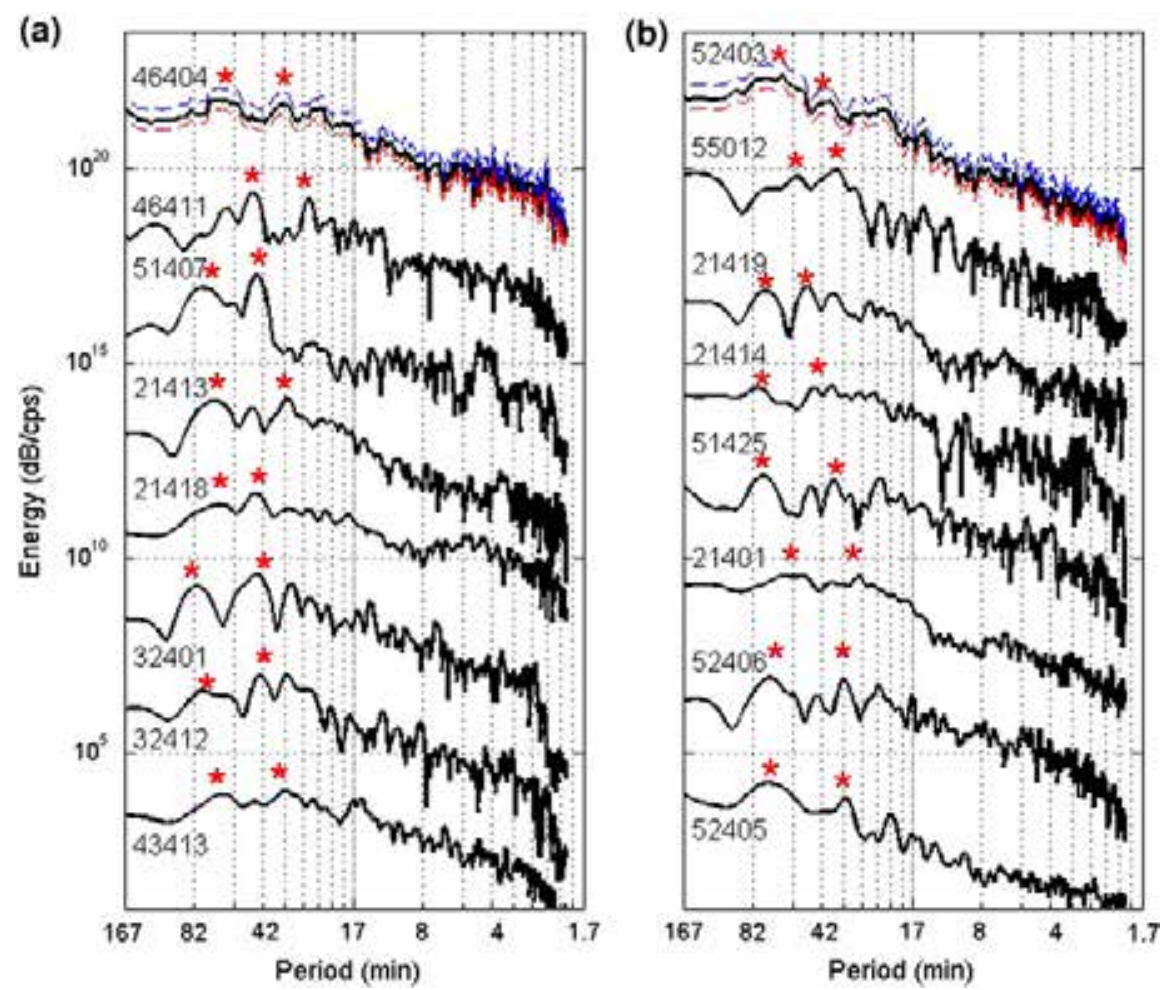

Figure 6

Spectral analysis for DART data. a Stations located perpendicular to the tsunami source strike and $\mathbf{b}$ those located at the directions parallel to the source strike (i.e., lateral stations). Stars show the two major peaks in each spectrum. For the two top spectra, the $95 \%$ confidence level is shown using red and blue dashed lines

concentrated in a relatively narrow band of 35-75 min for the rest of the tsunami oscillations. In DART station 51407, the tsunami energy is distributed in the period band of 35-75 min for the whole tsunami oscillations. In station 21414 , it seems that the two signals of 35-45 min and 60-75 min are arriving at the same time (circles in Fig. 7b). For the two far-field DART stations of 32412 and 43413, distinct lapses of high-energy content can be distinguished which are shown by circles and rectangles in Fig. 7a. Tsunami energy switches between the period bands of 3545 min (circles in Fig. 7a) and 60-75 min (rectangles in Fig. 7a) at different times. Time lapses of no energy content at the mentioned period bands are observable in $f-t$ plots too (arrows in Fig. 7a-b).

A clear difference can be seen between $f-t$ plots of DART (Fig. 7a, b) and tide gauge records (Fig. 7c-e). In general, energetic waves last for several days in the $f-t$ plots of the tide gauge records whereas they decay relatively faster in the $f-t$ plots of the DART records.
Figure $7 \mathrm{c}$ shows the $f-t$ plots for some near field tide gauge records in which some important features of tsunami energy behavior can be distinguished. It can be seen that the tsunami arrives in Naha with some delay because this station is located in a relatively farther distance to the tsunami source compared to other three stations (Fig. 7c). According to Fig. $7 \mathrm{c}$, the main tsunami energy is distributed in the period band of 10-80 min during the first $24 \mathrm{~h}$ after the earthquake, and then it is concentrated in a relatively narrower band. Temporal behavior of tsunami energy in Fig. 7c reveals that two or three signals are contributing at the same time to the tsunami energy. For example, the contributing signals to the tsunami energy in Omaezaki station are: 16-, 33- and 65-min signals. In Hanasaki, after the first $24 \mathrm{~h}$, most of the tsunami energy is concentrated around the period of $66 \mathrm{~min}$ for the rest of the tsunami oscillations. For Tosashimizu, two signals at the periods of around 22 and $40 \mathrm{~min}$ are acting at the 
(a) Some DART records
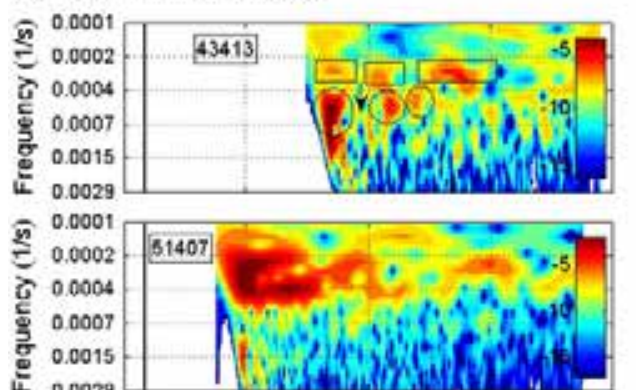

递 0.0029

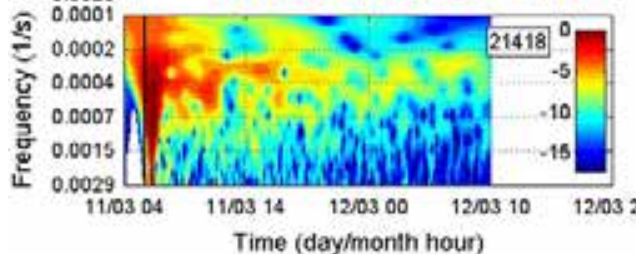

Time (day/month hour)

(b) Some DART stations
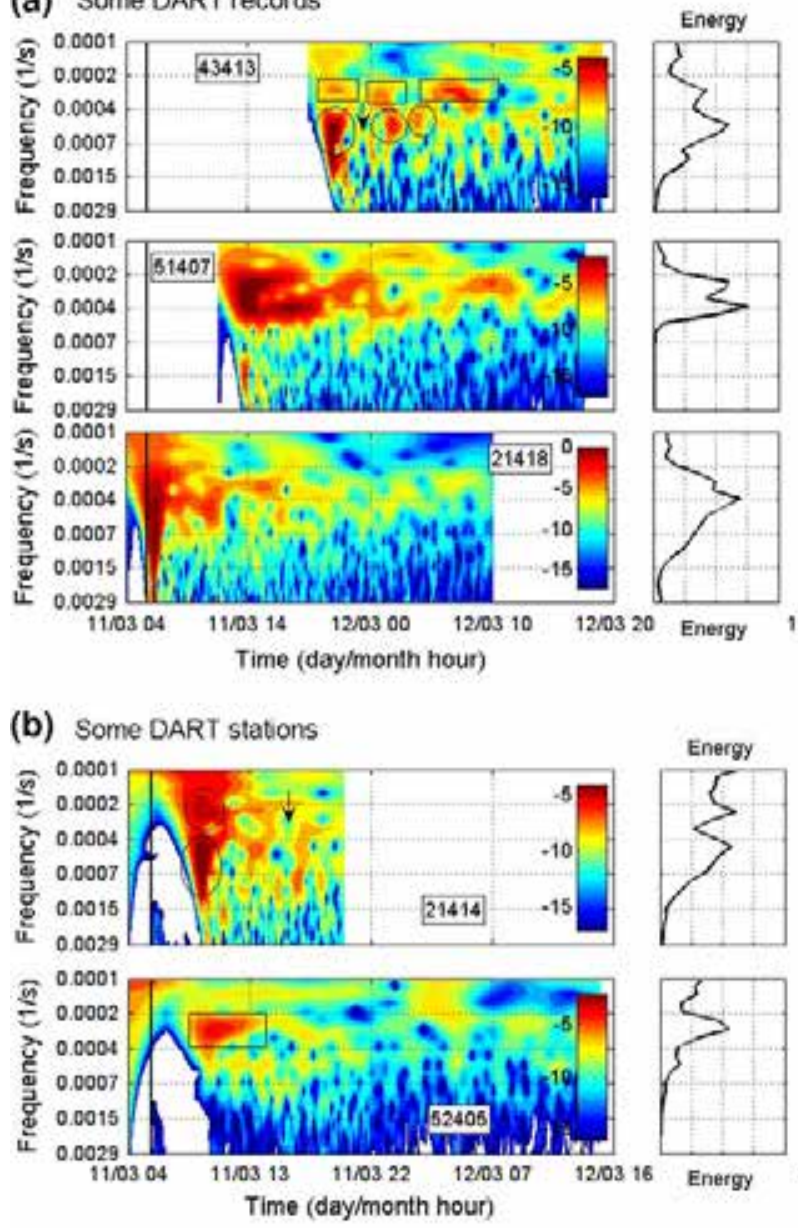

Energy
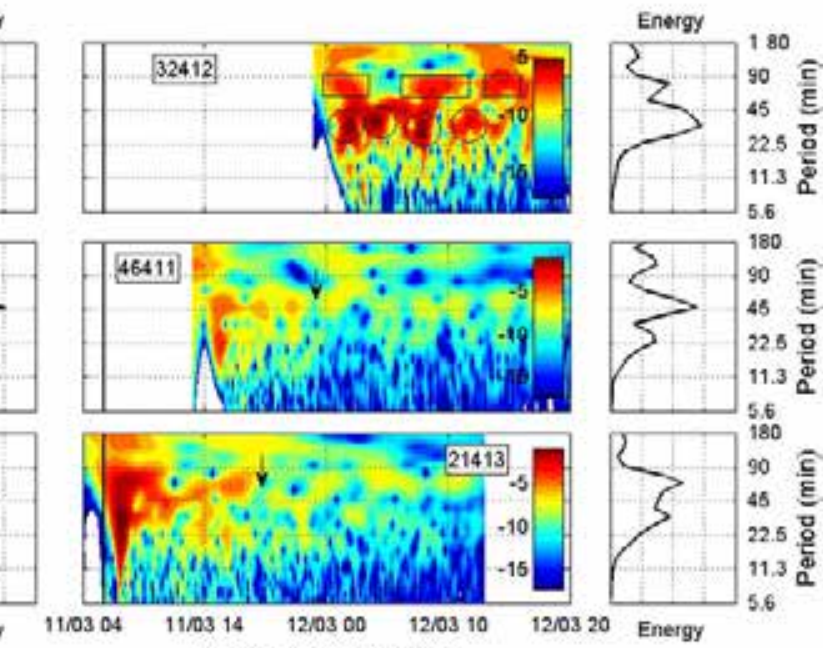

Time (day/month hour)

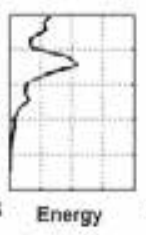

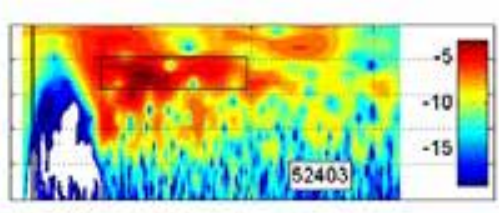
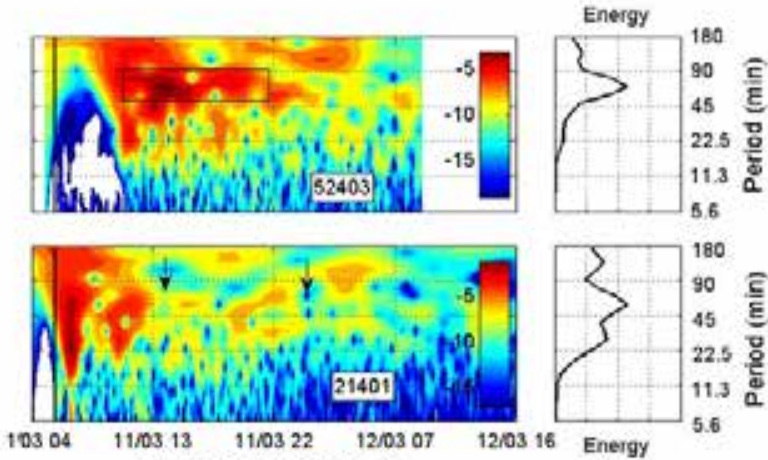

Time (day/month hour)

(c) Some near-field tide gauge stations
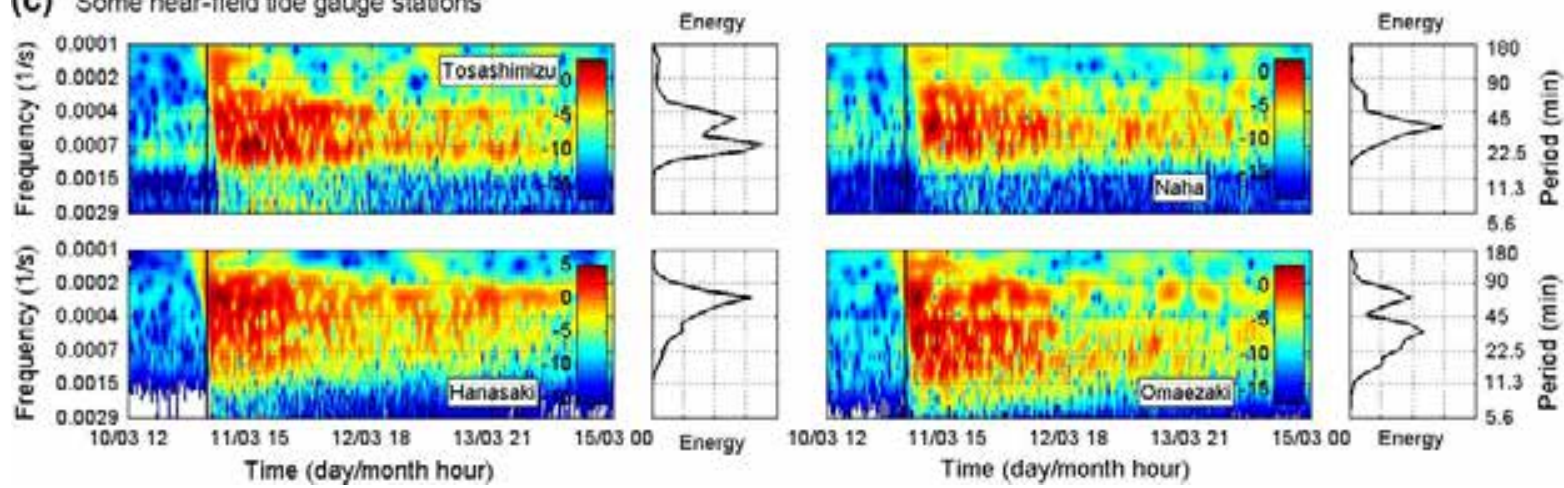

Time (dayimonth hour)

Figure 7

Wavelet analysis for selected DART and tide gauge stations. a DART stations located at the near perpendicular directions to the source strike, b DART stations located at the near parallel directions to the source strike, $\mathbf{c}$ tide gauge stations located in the near-field, $\mathbf{d}$ tide gauge stations located in some islands in the Pacific Ocean, and e tide gauge stations located across the Pacific Ocean. The thick vertical line represents the earthquake time. The color scale shows the logarithm of wave energy to the base 2 divided by 100 
(d) Some tide gauges in some Pacific Islands

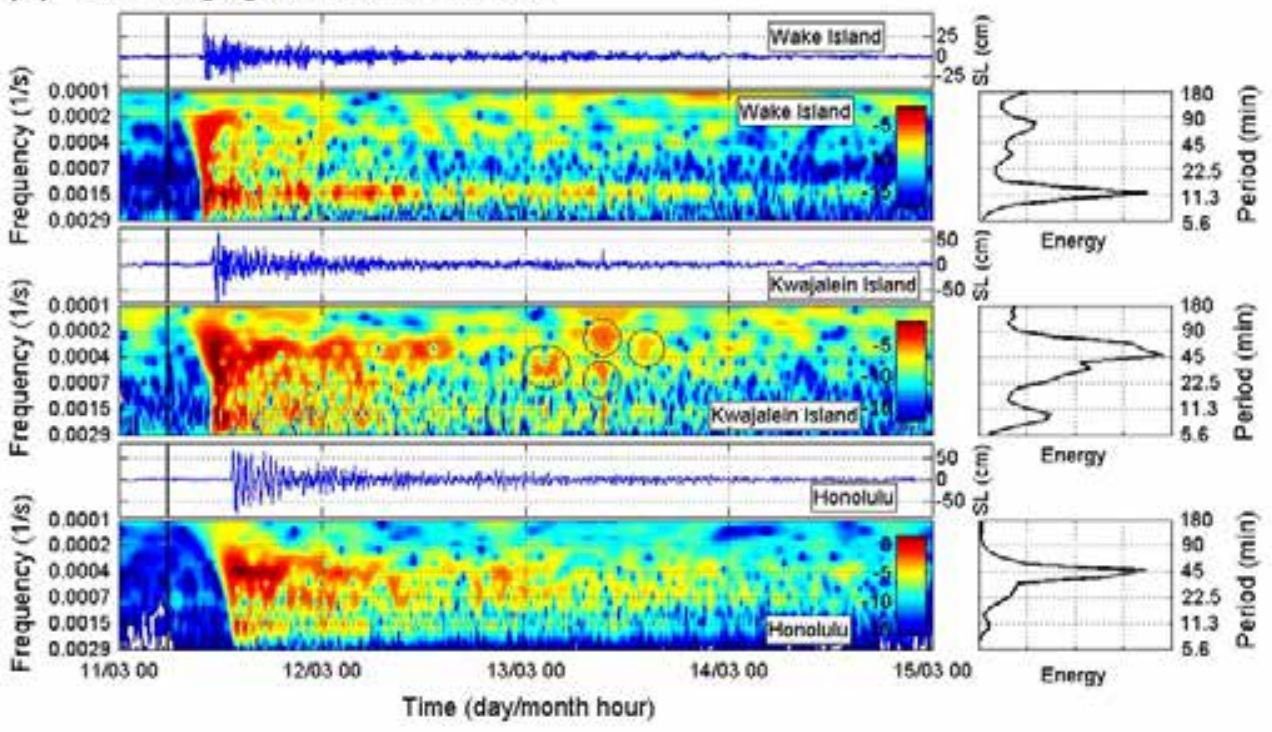

(e) Some far-field tide gauge stations

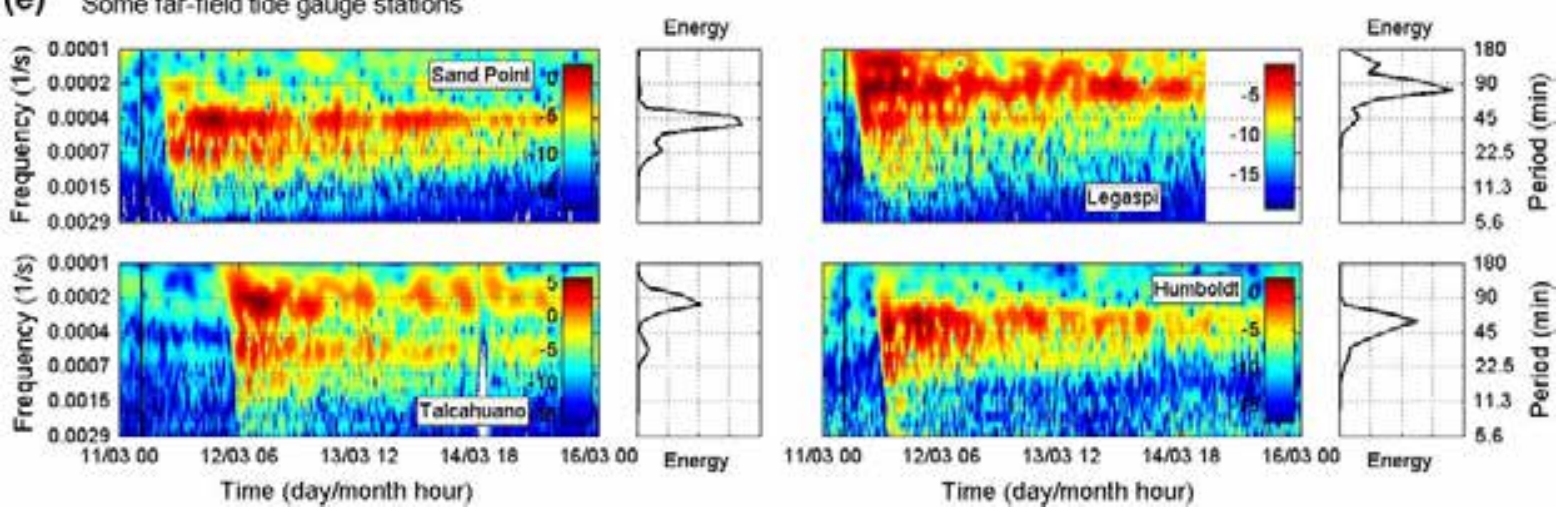

Figure 7

continued

same time for almost the whole tsunami oscillations. For the Naha record, Fig. 7c shows that the 35-min signal is governing for almost the whole tsunami oscillation time and other peak periods are evanescent peaks.

The wavelet analysis for some Pacific Island stations is shown in Fig. $7 d$. The $f-t$ plot for Wake Island shows that three signals at the periods of around 12, 33 and 72 min are acting simultaneously during the first hour after the tsunami arrival, and then most of the tsunami energy switches to the period band of $12 \mathrm{~min}$ for the rest of the tsunami oscillation. The 12-min signal also exists in the $f-t$ plots of Honolulu and Kwajalein records although they are not so strong. In both Kwajalein Island and Wake Island, tsunami energy occurs in a relatively wide period band of 10-80 min during the first hour after the tsunami arrival and then it is concentrated in a relatively narrow band. For the Kwajalein record, the $f-t$ plot shows that tsunami energy almost disappears on 12 March at around 16:00 GMT and then first laps of high-energy content occurs around $8 \mathrm{~h}$ later on March 13 at 02:00 GMT. Four lapses of high-energy content are shown by circles in Fig. 7d which contain 35- and 65-min signals.

These late lapses of high-energy contents which occur several hours after the tsunami generation are possibly reflected waves which still carry source 
signals. Based on the tsunami snapshots shown in Fig. 4d, several coastlines are candidates for tsunami wave reflection within the Pacific Basin. Figure $4 d$ shows that $2 \mathrm{~h}$ after the earthquake, the wave front arrives in the Kamchatka region of Russia (the Petropavlovsk station in Fig. 4d) where the first major wave reflection occurs. After around $6 \mathrm{~h}$, the wave front attacks the most of the western shorelines of the Pacific Basin (i.e., coastlines of the Philippines, Indonesia, and New Guinea). This will cause another major wave reflection and most of the reflected waves move towards the northern part of the Pacific Ocean. According to Fig. $4 \mathrm{~d}$, at around $t=10-14 \mathrm{~h}$, tsunami waves reach the western coast of the USA and the waves will be reflected towards the western shorelines of the pacific Basin (i.e., Japan and the Philippines).

Comparing the $f-t$ plots for some Pacific islands (Fig. 7d) with those of the near-field stations (Fig. 7c) shows that energy decay occurs relatively more rapidly in Pacific island stations. This is possibly because there is no shelf at the location of Pacific islands whereas near-field stations are located in the coastal areas and hence experience long oscillations due to the shelf/regional bathymetry effects.

Figure 7e presents the $f-t$ plots for some far-field stations. Compared to the near-field (Fig. 7c) and Pacific stations (Fig. 7d), it can be seen that tsunami energy is relatively less scattered. In all of these records, the two period bands of $35-45$ and 60 75 min are dominating. However, in Legaspi and Talcahuano, the 75-min signal is much stronger than the other one, whereas in Sand point, the 45-min signal is the stronger one.

\section{Discussions}

Comparison of DART and tide gauge records of the large 2011 Tohoku tsunami in this study gives us some clues about the characteristics of basin-wide oscillations of tsunamis. It was shown above that the average duration of tsunami oscillation is about 4 days on tide gauge stations whereas it is about 2 days on DART stations. This may indicate that a large part of tsunami oscillations in the coastal areas is due to the effects of continental shelves, regional and local bathymetry, and bays and harbors because long tsunami waves entering continental shelves or coastal bays and harbors can be trapped and experience persistent oscillations. Although this finding is not new, this study shows that around half of the long tsunami oscillations in the coastal areas can be attributed to shelf/bay/harbor effects. This observation is in agreement with the study by Dengler and UsLu (2011) who showed that bathymetry of the coastal areas has significant effects on the amplification of tsunami waves. Watanabe (1972) made efforts to explain the pattern of wave-form and the maximum wave height of large tsunamis.

To estimate the tsunami source dimensions (width, $W$; and length, $L$ ) from dominant tsunami periods, we apply the following equation:

$$
\lambda=T \sqrt{\mathrm{gh}},
$$

where $\lambda$ is tsunami wavelength in meters, $\mathrm{g}$ is the gravitational acceleration in $\mathrm{m} / \mathrm{s}^{2}, \mathrm{~h}$ is ocean water depth at the source area in meters, and $T$ is the dominant period of tsunami in seconds. It is normally assumed that tsunami wavelengths are up to twice the length or width of the source fault. The ocean water depth ranges between 2,000 and $7,000 \mathrm{~m}$ in the source area of the 2011 Tohoku earthquake; hence an average water depth of $4,500 \mathrm{~m}$ is considered here. Using the two dominant periods of 37 and $67.4 \mathrm{~min}$ for the 2011 Tohoku tsunami (Table 5), application of Eq. (5) results in 233 and $424 \mathrm{~km}$ for the width and length of the tsunami source fault, respectively. This estimation agrees with the reports of FuJII et al. (2011) and Yoshida et al. (2011) who estimated the source dimensions of the 2011 Tohoku tsunami as $450 \mathrm{~km} \times 200 \mathrm{~km}$.

Our analysis of the tide gauge records of the 2011 large Tohoku tsunami showed that large trans-oceanic tsunamis can be associated with complicated behavior. It is not new that tsunamis can travel thousands of kilometers without losing the most part of their energy as it was evidenced in some large trans-oceanic tsunamis in the past. For example, the 1960 Chilean tsunami caused 61 fatalities and extensive damages in Hilo Bay, Hawaii at the distance of about $10,000 \mathrm{~km}$ from the tsunami source (Liv et al. 1995). The other important example in this 
context is the 1964 Alaskan tsunami which caused a death toll of 10 in Crescent City, California (LANDER et al. 1993). However, it is rare that a tsunami could cause a wave height of about $4 \mathrm{~m}$ on a tide gauge at the distance of $17,500 \mathrm{~km}$ from the tsunami source as the 2011 Tohoku tsunami did on the Chilean coast. It should be recalled that the 1960 Chilean tsunami generated by an $\mathrm{Mw} 9.5$ earthquake produced runup heights up to 5-7 $\mathrm{m}$ on the Japanese coast; in a symmetry to the 11 March 2011 Tohoku tsunami.

It has been reported in the literature that wave dispersion plays an important role in the far-field propagation of tsunamis (KuliKov 2006). Due to the dispersion effect, longer waves propagate more rapidly than the shorter ones, and hence, tsunami waves are divided into trains of waves as they travel long distances (e.g., trans-oceanic tsunamis). This phenomenon which usually causes noticeable effects on landslide tsunamis or large trans-oceanic ones has been reported to be responsible for some unusual tsunami observations in the past. KaTO et al. (2011) noticed that the 10-30 min component in the tsunami waveforms recorded offshore Japan due to the 27 February 2010 Chilean tsunami, arrived 26 min later than the longer period components $(T>60 \mathrm{~min})$. Based on our wavelet analysis (Fig. 7), it can be seen that the first waves arriving at most of the stations examined in this study are always the long-period waves ( $T>60 \mathrm{~min}$, see Fig. 7) which may be attributed to the dispersion effect.

Based on our analysis of tide gauge records of the 2011 Tohoku tsunami, we noticed that in many coastal stations the largest wave arrived several hours after the first arrival of the tsunami wave. Although this finding is not new, the difference between the arrival time of the first wave and that of the maximum wave in some stations seems too large for the 2011 Tohoku tsunami. In Sand Point, Alaska, the largest wave arrived almost half a day after the first arrival. From the tsunami hazard point of view, the arrival of the largest wave several hours later than that of the first wave can be hazardous for local people as they may not be informed about the late arrival of the largest tsunami waves.

It was shown that the oscillations caused by the 2011 Tohoku tsunami persisted for several days in some locations across the Pacific Ocean. It is evident that such long duration time poses a major difficulty for authorities to clear tsunami warnings because in the case of a large trans-oceanic tsunami, the alarm should be raised for some days. It seems difficult to convince people to stay away from the shoreline for 1 or 2 days. Therefore, it is necessary that the local people could be educated about the complex behavior of large trans-oceanic tsunamis and the fact that they have to stay away from the shoreline until the tsunami alarm is cancelled.

\section{Conclusions}

We studied the 2011 large Tohoku tsunami offshore northeast Japan by analyzing 21 tide gauge and 16 DART records from across the Pacific Ocean. The main findings are:

1. Tsunami signal was easily identifiable in all of the analyzed sea level record as far as the western coast of the USA and the southern coast of Chile indicating that the 11 March 2011 Tohoku tsunami was a trans-oceanic one. Among the examined tide gauge stations, the maximum trough-to-crest amplitude was $394 \mathrm{~cm}$ recorded at the Coquimbo station in Chile, about $17,500 \mathrm{~km}$ away from the source. The average value of the maximum trough-to-crest amplitude of the tsunami was $163.9 \mathrm{~cm}$. In most of the examined tide gauge records, the largest wave was not the first one and arrived several hours after the first arrival of the tsunami waves. In Sand Point station, Alaska, the largest wave arrived more than $12 \mathrm{~h}$ after the arrival of the first wave. The tsunami waves persisted for several days in most of the analyzed tide gauge stations. The average duration of tsunami oscillations on the tide gauge stations was 4 days. For Pacific Island stations, the tsunami signal has a relatively shorter duration which is possibly due to the lack of continental shelf at the location of these stations.

2. The DART data shows different characteristics of the trans-oceanic tsunami recorded in deep ocean. First, the first wave was the largest one in most of the DART stations whereas it was not the largest one in most of the tide gauge stations. Second, the 
average value of the maximum trough-to-crest tsunami amplitude was $51.2 \mathrm{~cm}$ for the examined DARTs which is more than three times less than that for the tide gauges. Third, the average duration of tsunami oscillations is 2 days for DARTs which is half of that for tide gauges. Based on the spectral analysis of the DART records, the two main tsunami source periods are 37 and $67.4 \mathrm{~min}$ which are possibly attributed to the width and length of the tsunami source fault, respectively. The strike-normal stations show a governing period of $37 \mathrm{~min}$, while the lateral stations show that the two periods are equally dominant. Using these peak periods, the dimensions of the tsunami source is estimated as $424 \mathrm{~km} \times 233 \mathrm{~km}$.

3. Wavelet analyses showed that the tsunami energy occurs in a relatively wide period band of 10-80 min during the first hour after the tsunami arrival, and then, it is concentrated in a relatively narrower band. The $f-t$ plots show that tsunami energy switches between the period bands of 35-45 $\mathrm{min}$ and 60-75 min at different times. Lapses of high-energy content are observed in the $f-t$ plots which contain 35-min and 65-min signals several hours after the tsunami arrival. These late lapses of high-energy contents are possibly reflected waves which still carry tsunami source signals.

\section{Acknowledgments}

The wavelet package by TORRENCE and COMPO (1998) was used in this study. The tide gauge data used in this study were provided through the Japan Coast Guard (JCG), USA National Oceanographic and Atmospheric Administration (NOAA), and UNESCO Intergovernmental Oceanographic Commission (IOC). The first author is grateful to the Matsumae International Foundation in Japan (MIF) for supporting this research. This article benefited from detailed reviews by Prof. Alexander Rabinovich (the editor) and two anonymous reviewers. We sincerely thank them for the comments that improved this article.

\section{REFERENCES}

Asiaone (2011). One killed as tsunami hit Indonesian shores, news published on March 13, 2011 available at: http://news.asiaone. com/News/Latest\%2BNews/Asia/Story/A1Story20110313-267835. html.

Ben-Menahem, A., and Rosenman, M. (1972). Amplitude patterns of tsunami waves from submarine earthquakes, J. Geophys. Res., 77:3097-3128.

Bernard, E.N., González, F.I., Meinig, C., and Milburn, H.B. (2001). Early detection and real-time reporting of deep-ocean tsunamis, Proc. Int. Tsunami Symp. 2001, Seattle, WA, pp. 97-108.

Dengler, L., and Uslu, B. (2011). Effects of Harbor Modification on Crescent City, California's Tsunami Vulnerability, Pure App. Geophys., 167 (6-7):1175-1185.

Dragani, W.C., D'onofrio, E.E., Grismeyer, W., Fiore, M.E. (2006). Tide gauge observations of the Indian ocean tsunami, December 26, 2004, in Buenos Aires coastal waters, Argentina, Cont. Shelf Res., 26:1543-1550.

Fire and Disaster Management Agency of Japan (2011). available at: (http://www.fdma.go.jp/en/), page visited on Jan. 5, 2012.

Fuji, Y., and Satake, K. (2007). Tsunami Source of the 2004 Sumatra-Andaman Earthquake inferred from Tide Gauge and Satellite Data, Bull. Seism. Soc. Am., 97(1A):S192-S207.

Fuji, Y., Satake, K., Sakai, S., Shinohara, M., Kanazawa, T. (2011). Tsunami source of the 2011 off the Pacific coast of Tohoku Earthquake, Earth Planets Space, 63:815-820.

Goupillaud, P., Grossman, A., and Morlet, J. (1984). CycleOctave and related transforms in seismic signal analysis, Geoexploration, 23:85-102.

IOC, IHO, BODC (2003). Centenary edition of the GEBCO digital atlas, published on CD-ROM on behalf of the Intergovernmental Oceanographic Commission and the International Hydrographic Organization as part of the general bathymetric chart of the oceans. British oceanographic data centre, Liverpool.

JCG (Japan Coast Guard) (2011), Hydrographic and Oceanographic Department, at: http://www1.kaiho.mlit.go.jp/KANKYO/TIDE/ real_time_tide/sel/index_e.htm (visited on December 2011).

Joseph, A., Odametey, J.T., Nkebi, E.K., Pereira, A., Prabhudesai, R.G., Mehra, P., Rabinovich, A.B., Kumar, V., Prabhudesai, S., WoOdWORTH, P. (2006). The 26 December 2004 Sumatra tsunami recorded on the coast of West Africa, Afr. J. Mar. Science, 28(3\&4):705-712.

IOC (Intergovernmental Oceanographic Commission), 2011, Sea Level Station Monitoring Facility, at: http://www.ioc-sealevelmonitoring. org/map.php (visited on December, 2011).

KAISER, G. (1994). A Friendly Guide to Wavelets. Birkhäuser, $300 \mathrm{p}$.

Kato, T., Terada, Y., Nishimura, H., Nagai, T., and Koshimura, S. (2011). Tsunami records due to the 2010 Chile Earthquake observed by GPS buoys established along the Pacific coast of Japan, Earth Planets Space, 63:e5-e8.

Kulikov, E.A., Rabinovich, A.B., Thomson, R.E., Bornhold, B.D. (1996). The landslide tsunami of November 3, 1994. Skagway Harbour, Alaska, J. Geophys. Res., 10 (C3):6609-6615.

Kulikov, E (2006). Dispersion of the Sumatra Tsunami waves in the Indian Ocean detected by satellite altimetry, Russ. J. Earth Sci. 8, ES4004, doi:10.2205/2006ES000214. 
LANDER, J.F., Lockridge, P.A., and Kozuch, M.J. (1993). Tsunamis Affecting the West Coast of the United States 1806-1992, NGDC Key to Geophysical Record Documentation No. 29, NOAA, NESDIS, NGDC, 242 p.

Liu, P.L.F., Cho, Y.S., Yoon, S.B., and Seo, S.N. (1995). Numerical simulations of the 1960 Chilean tsunami propagation and inundation at Hilo, Hawaii, in: Tsunami: Progress in Prediction, Disaster Prevention and Warning, Y. TSUCHIYA and N. SHUTO (eds.), Kluwer Academic Publishers, 99-115.

MATHWorks (2012). MATLAB user manual, The Math Works Inc., MA, USA, $282 \mathrm{p}$.

NOAA (National Oceanographic and Atmospheric Administration), 2011, Center for Operational Oceanographic Products and Services (CO-OPS), National Ocean Service (NOS), at: http://tidesandcurrents.noaa.gov/tsunami/\# (visited on December 2011).

Окара Y. (1985). Surface deformation due to shear and tensile faults in a half-space, Bull. Seismol. Soc. Am., 75(4):1135-1154.

Oppenheim, A.V. and, Schafer, R.W., (1975). Digital signal processing. Prentice-Hall publications, Englewood Cliffs, NJ, USA, ISBN 0-13-214635-5, 585 p.

Rabinovich, A.B. (1997). Spectral analysis of tsunami waves: Separation of source and topography effects, J. Geophys. Res., 102 (12):663-676.

Rabinovich, A.B., and Thomson, R.E. (2007). The 26 December 2004 Sumatra Tsunami: Analysis of Tide Gauge Data from the World Ocean Part 1. Indian Ocean and South Africa, Pure App. Geophys., 164:261-308.

Rabinovich, A.B., Thomson, R.E., and Stephenson, F.E.(2006). The Sumatra tsunami of 26 December 2004 as observed in the North Pacific and North Atlantic Oceans. Surv. Geophys., 27:647-677.

SATAKE, K. (1988). Effects of bathymetry on tsunami propagation: application of ray tracing to tsunamis, Pure App. Geophys., 126 (1):27-36.
Satake, K., and Kanamori, H. (1991). Use of tsunami waveforms for earthquake source study, Nat. Hazards, 4:193-208.

TAKAHASHI, S., et al. (2011). Urgent survey for 2011 great east Japan earthquake and tsunami disaster in ports and coasts, Technical note of the Port and Airport and Research Institute (PARI), No. 1231, April 2011, 200 p (in Japanese with English abstract).

Titov, V., Rabinovich, A.B., Mofjeld, H.O., Thomson, R.E., and GonZALEZ, F.I. (2005). The global reach of the 26 December 2004 Sumatra tsunami. Science 309:2045-2048.

Torrence, C., and Compo, G.P. (1998). A practical guide to wavelet analysis. B. Amer. Meteor. Soc. 79 (1):61-78.

USGS (US Geological Survey), (2011), Earthquake online catalog: Magnitude 9.0- Near the coast of Honshu, Japan. Available at: (http://earthquake.usgs.gov/earthquakes/recenteqsww/Quakes/usc 0001xgp.php), page visited on Jan. 5, 2012.

Watanabe, H. (1972). Statistical studies on the wave-form and maximum height of large tsunami, J. Oceanogr. Soc. Japan 28:229-241.

Welch, P. (1967). The use of fast Fourier transform for the estimation of power spectra: A method based on time averaging over short, modified periodograms, IEEE Trans. Audio Electroacoust AE-15:70-73.

WfaA, (2011), Tsunami sweeps 5 to sea, California and Oregon sustain damage, news published on March 11, 2011, available at: http://www.wfaa.com/news/world/Tsunami-sweeps-5-to-sea-dam age-to-Calfi-and-Ore-117827733.html.

Yoshida, Y., Ueno, H., Muto, D., Aoki, S. (2011). Source process of the 2011 off the Pacific coast of Tohoku Earthquake with the combination of teleseismic and strong motion data. Earth Planets Space 63:565-569. 